\title{
El David en pañales: \\ censura e intervención urbana en la postdictadura
}

\author{
Michelangelo's David in diapers: post-dictatorship censorship \\ and urban intervention
}

\section{Leandro Delgado*}

\footnotetext{
* Licenciado en Comunicación por la Universidad Católica del Uruguay. MA en Mass Communication por la Universidad de Leicester (Reino Unido) y PhD en Literatura Hispanoamericana por la Universidad de Rutgers (Nueva Jersey, EUA). Profesor de grado y maestría en el Departamento de Comunicación de la Universidad Católica del Uruguay. Investigador, escritor y editor. 凶ledelgad@ucu.edu.uy
}

https://orcid.org/0000-00019485-766X

RECIBIDO: [2.9.2018]

ACEPTADO: [26.11.2018]

\section{Resumen}

La censura al artista Óscar Larroca en 1986 por el intendente Jorge Luis Elizalde generó una repercusión desmedida en la prensa montevideana, producto de una manipulación periodística que vulneró definitivamente los derechos del artista. La primera parte de este artículo reconstruye y describe los conflictos entre los gobiernos municipal y nacional alrededor de este acontecimiento, los cuales enfrentaron a los sectores batllistas y pachequistas del Partido Colorado. También presenta las formas de represión internalizadas y asumidas por los políticos de la nueva democracia después de doce años de ausencia casi total de debate público. La segunda parte describe la intervención anónima inmediata en el David, escultura ubicada en la fachada de la Intendencia Municipal de Montevideo, en respuesta a esta censura, la cual es analizada desde las concepciones urbanas de Michel de Certeau y Ángel Rama.

Palabras clave: historia cultural, censura, Uruguay, prensa.

\section{Abstract}

Artist Óscar Larroca censorship in 1986 by mayor Jorge Luis Elizalde, generated disproportionate media 
repercussions in Montevideo, product of a journalistic manipulation that definitively undermined the artist's rights. The first part of this article reconstructs and describes the conflicts between the municipal and national governments over this event, which confronted the Batllista and Pachequista sectors of the ruling Colorado Party. It presents as well the forms of repression internalized and assumed by the politicians of the new democracy after twelve years of almost total absence of public debate. The second part describes the immediate anonymous intervention on the statue of David, which adorns the facade of Montevideo City Hall, in response to this censorship, which is analyzed from the urban conceptions of Michel de Certeau and Ángel Rama.

Keywords: cultural history, censorship, Uruguay, press.

Si el miedo y la destrucción

son las principales fuerzas emocionales del fascismo, eros pertenece principalmente a la democracia.

Theodore W. Adorno

En noviembre de 1984 se celebraron en Montevideo las primeras elecciones departamentales luego de la dictadura (1973-1984). El intendente electo fue el médico y diputado Aquiles Lanza, quien estuvo apoyado por los sectores batllistas del Partido Colorado. A nueve meses de iniciada su gestión, Lanza murió a consecuencia de una crisis cardíaca. El primer suplente, Julio Grauert, también había muerto meses antes, por lo cual asumió el cargo el segundo suplente en la lista, Jorge Luis Elizalde, ${ }^{1}$ un abogado y antiguo funcionario municipal, quien hasta ese momento ocupaba la dirección del Departamento Jurídico de la Intendencia Municipal de Montevideo (IMm) («Un profesor...», 1985, p. 11). Desde su lugar de segundo suplente, parecía claro que ni el Partido Colorado ni el mismo Elizalde pensaban que ocupara ese cargo, uno de los más disputados en la estructura de gobierno departamental y nacional.

Elizalde figuraba como segundo suplente de Lanza en representación de la lista 85, Libertad y Cambio (agrupación batllista liderada por el vicepresidente Enrique Tarigo), pero a partir de su actividad política previa a la dictadura el intendente era

\footnotetext{
Abogado, catedrático de la Facultad de Derecho en Técnica Forense y miembro de las comisiones de Constitución y Electoral del Partido Colorado, Jorge Luis Elizalde había comenzado su actividad política en 1950, en la lista 14, acompañando a Cesar Mayo Gutiérrez. Luego acompañó a Luis Batlle Berres y llegó a ser electo diputado por el departamento de Tacuarembó. En 1967 apoyó a Glauco Segovia, quien ejerció como intendente de Montevideo de febrero a octubre de ese año. Más adelante, Elizalde estuvo fuertemente vinculado al pachequismo en las elecciones de 1971. («Un profesor...», 1985, p. 11).
} 
identificado con el pachequismo, un sector ubicado a la derecha del batllismo, representado este en la figura del nuevo presidente, Julio María Sanguinetti. En efecto, Elizalde no tenía una buena relación con los hombres de confianza designados por su antecesor, entre ellos los responsables del Departamento de Cultura de la IMM, creado durante la gestión de Lanza. Los directores del Departamento, Thomas Lowy y Alejandro Bluth, eran representantes de la Corriente Batllista Independiente (CBI), un sector socialdemócrata integrado por políticos jóvenes que se ubicaba a la izquierda del batllismo en el espectro ideológico del partido. A principios de ese mismo año, los enfrentamientos con el intendente habían llegado a la casi sustitución de sus directores, la que finalmente logró evitarse gracias a acuerdos llevados adelante por el senador Manuel Flores Silva, líder político de la CBI («Dibujos de Larroca...», 1986, p. 15).

La desconfianza hacia Elizalde no provenía solamente de parte de la opinión pública por su adhesión al pachequismo. ${ }^{2}$ A pocos meses de su gestión, comenzaron a hacerse públicas algunas irregularidades, denunciadas por los ediles del Frente Amplio Artigas Melgarejo y Rafael Michelini, quienes solicitaron un informe que diera cuenta de situaciones que no consideraban claras: deterioro de paseos públicos y espacios verdes, pagos a empresas privadas por servicios no prestados, obras públicas sin finalizar y falta de información sobre algunas licitaciones. ${ }^{3}$

De allí en más, la breve carrera de Elizalde estuvo marcada por una serie de acontecimientos infelices y escandalosos que tuvieron como inicio espectacular la censura a la muestra del dibujante Óscar Larroca, quien iba a presentar una serie de desnudos en la sala de exposiciones del edificio de la IMM. Este acontecimiento adquirió tal resonancia que tomó un lugar central en la prensa de la nueva democracia y permitió ver, en primer lugar, cómo las disputas en el terreno de la cultura eran expresiones de conflictos políticos en un país que no estaba habituado al debate público. En segundo lugar, permitió visualizar los mecanismos represores del gobierno anterior que sobrevivían no solo en aquellos sectores políticos que apoyaron al régimen, sino también en la represión internalizada por los políticos de la oposición luego de doce años de dictadura, como se analizará.

Con la restauración democrática, la figura del expresidente Pacheco Areco se identificaba con la represión previa a la dictadura, así como con el mismo proceso dictatorial: ocupó puestos de embajador uruguayo en España, Suiza y Estados Unidos y adhirió a la reforma constitucional de 1980 promovida por el gobierno militar y rechazada en el plebiscito de ese año.

3 Se trataba del incumplimiento de las obligaciones de empresas contratadas para el mantenimiento de espacios verdes, las condiciones de trabajo en la reparación de los hornos del Cementerio del Norte y el asesoramiento técnico erróneo sobre los servicios de impermeabilización del desaparecido Cilindro Municipal. Las denuncias de los ediles de la oposición no fueron infundadas y las irregularidades estuvieron confirmadas, situación que llevó a Elizalde a cesar de su cargo al director de la División de Obras y Proyectos, Julio César Bustelo. («Presuntas irregularidades», 1986). 


\section{La censura}

En 1986, Óscar Larroca era un dibujante muy joven que había tenido un rápido reconocimiento de la crítica por sus dibujos en grafito. A los 19 años ya había ganado un concurso organizado por Cinemateca Uruguaya que le permitió realizar su primera exposición individual. En ese mismo año (1981) una obra suya fue premiada en la Primera Muestra de Plásticos Jóvenes. Allí el hiperrealismo se fundía con imágenes surrealistas y oníricas anunciando una obra de creciente complejidad que presentaba los elementos de la tortura física y psicológica de la dictadura militar. A partir de 1984, su obra comenzó a tratar el cuerpo desnudo, el erotismo y la sexualidad, llevando el hiperrealismo a un grado de mayor detalle. El tratamiento de la sexualidad en sus obras fue el motivo de la censura que lo afectaría dos años más tarde. Si bien se puede considerar un artista autodidacta, Larroca había tenido inicialmente la guía del artista plástico Manuel Espínola Gómez, quien le aportó elementos sobre la concepción y la filosofía del arte hasta el punto de que, con los años, Larroca llegó a publicar estudios sobre arte y erotismo (Da Cruz, 2010).

Espínola Gómez, considerado entonces un «maestro» en el panorama de las artes plásticas de Uruguay, era asesor plástico de la Presidencia así como de la IMM (Haber, s/f). En este cargo recomendó a Larroca y al dibujante Diego Legrand a los directores del Departamento de Cultura para realizar una muestra conjunta en la sala de exposiciones sobre la calle Soriano, luego clausurada en la intendencia de Tabaré Vázquez. El propio Espínola Gómez había sido el autor del texto del catálogo («Estética...», 1986, p. 16). En esta muestra, Larroca presentaba su producción más reciente, aquella que incluía su incursión en la sexualidad y el erotismo.

En julio de 1986, el Departamento de Cultura invitó públicamente a la inauguración para el viernes 1 de agosto. Sin embargo, esa misma tarde, cuando todo estaba listo, el intendente fue notificado por un funcionario municipal acerca de las características de las obras. Al verlas, Elizalde decidió cancelarla muestra y ordenó colocar un cartel indicando que la exhibición no iba a inaugurarse «por problemas técnicos de luz» («Dibujos de Larroca...», 1986, p. 15). Con la intermediación de los directores del Departamento de Cultura, el intendente solicitó el retiro de tres obras en particular, por considerarlas «obscenas» (figuras 1, 2 y 3).

La propuesta de retirar estas obras no fue aceptada por el artista, por lo cual la inauguración se mantuvo en suspenso. Al mismo tiempo, se iniciaba un proceso de conversaciones entre autoridades gubernamentales y municipales que fue adquiriendo repercusión creciente. La «obscenidad» acusada por el intendente tuvo eco inmediato en la prensa $\mathrm{y}$, a partir de entonces, los titulares de portada abundaron en alusiones a la pornografía, como puede verse en estos tres titulares sucesivos del diario $E l$ País. 
«Pornografía Oficializada».

(El País. Lunes 11 de agosto de 1986, p. 2)

«Pedido de informes a Reta y Elizalde por Muestra Pornográfica».

(El País. Martes 12 de agosto de 1986, p. 1)

«Intendente: Obras van Hasta las Perversiones Sexuales»

(El País. Miércoles 13 de agosto de 1986, p. 7)

Este artículo no va a indagar en las distinciones entre erotismo y pornografía ni en el tratamiento de la sexualidad y del erotismo en la obra de Larroca, que serían, por sí mismos, objetos de otro estudio. El análisis indaga en la manipulación periodística y en las probables razones de la desmesura en la reacción de la prensa y de figuras políticas que, finalmente, lograron construir un acontecimiento que marcó el debate acerca de lo que podía o no ser exhibido frente al público.

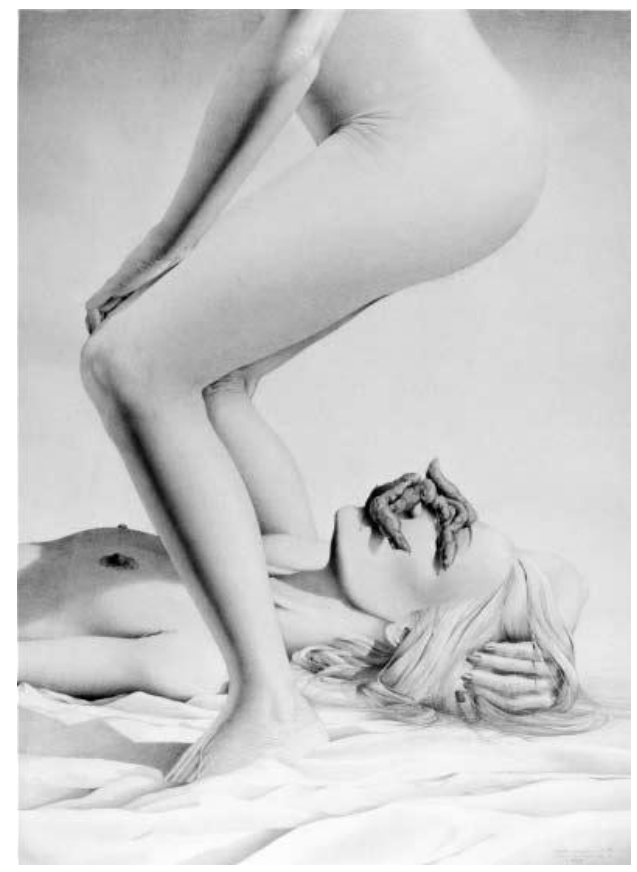

Figura 1. Autodestrucción II (papel Canson sobre grafito). Fuente: www.larrocaoscar.com 
Figura 2. La cena (papel Canson sobre grafito). Fuente: www.larrocaoscar.com

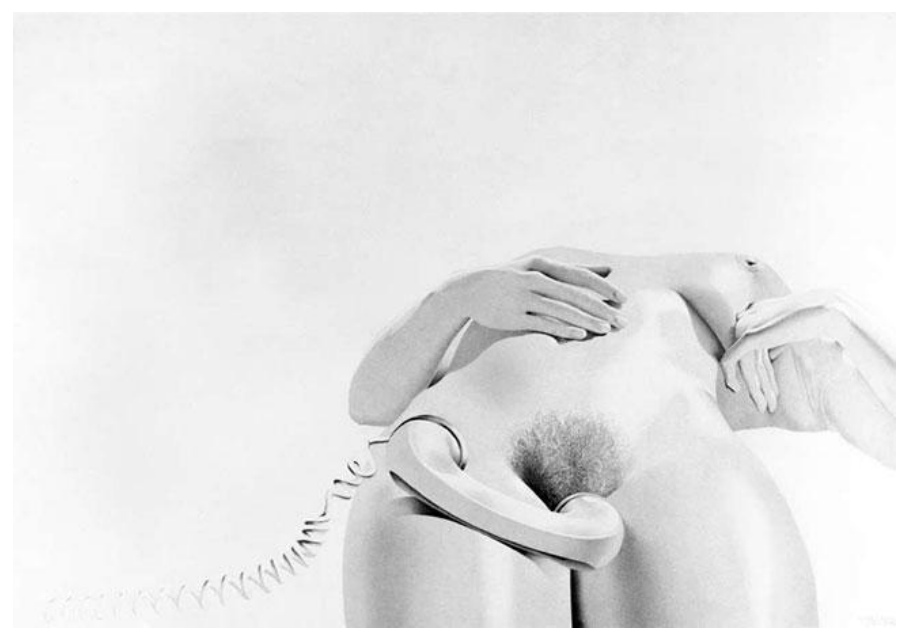

Figura 3. Uno de esos días (papel Canson sobre grafito). Fuente: www.larrocaoscar.com

La decisión de Elizalde entró rápidamente en conflicto con el mismo gobierno nacional, y el lunes 11 se iniciaron conversaciones entre autoridades municipales y del Ministerio de Educación y Cultura (MEC). Esas conversaciones culminaron el miércoles 13 en el edificio de la Presidencia de la República, donde se reunieron el presidente interino, Enrique Tarigo, la ministra de Educación y Cultura, Adela Reta, y el propio inten- 
dente. En esa reunión se enfrentaron la posición del Poder Ejecutivo con la de Elizalde, ya que la decisión de prohibir la muestra había sido del intendente a título personal.

Según afirmaba el semanario Búsqueda a la mañana siguiente, el Poder Ejecutivo había propuesto que las obras se expusieran en el ámbito del Servicio de Teatros $\mathrm{Mu}$ nicipales, pero esta iniciativa tampoco contó con el aval de Elizalde («Dibujos de Larroca...», 1986, p. 15). El viernes 8, el Servicio de Publicaciones y Prensa de la IMM emitió un comunicado para explicar los motivos de la cancelación definitiva de la muestra. ${ }^{4}$ Por otra parte, en una carta enviada por Elizalde a la Junta Departamental, este relató cómo y cuándo fue advertido del carácter «pornográfico» de las obras y la inconveniencia de exhibirlas en una sala que se encontraba en el camino al ascensor panorámico de la ciudad, por el cual se accedía al mirador municipal, atractivo turístico visitado por grupos de escolares y liceales («Puntualizaciones...», 1986)

El conflicto entre el gobierno central y el municipal se puede ver, en primera instancia, como una disputa por el poder dentro del Partido Colorado, es decir, entre los sectores batllistas y pachequistas, una polarización que se arrastraba desde sus posiciones respectivas frente a la dictadura y en los años previos al golpe de Estado. La polarización se repetía ahora en la misma administración municipal, es decir, entre los directores del Departamento de Cultura y el intendente, y se prolongaría en otros conflictos también vinculados con iniciativas culturales promovidas por los jóvenes directores del Departamento. ${ }^{5}$

«La Intendencia Municipal de Montevideo, ante la situación creada en torno a la decisión de esta Administración de suspender la muestra plástica que el artista Óscar Larroca iba a realizar en el Centro de Exposiciones del Palacio Comunal, a solicitud del Departamento de Cultura, aclara: 1) Nada más lejano del espíritu de esta Intendencia que el coartar, de manera alguna, la libertad creativa de los artistas nacionales. Pero así como es obligación evitar agresiones a la libertad creadora, también es nuestro deber proteger los legítimos derechos de aquellos que pudieran eventualmente, sentirse lesionados ante lo que podrían considerar un desborde en el uso de esa libertad. 2) No es materia de esta Administración determinar si la exposición referida es o no lasciva para la sensibilidad media de los ciudadanos, pero ante la posibilidad de que efectivamente así resultara, se ha considerado pertinente la no utilización del Centro de Exposiciones del Palacio Municipal. Considerando: 1) que la naturaleza de esta muestra ha provocado un cúmulo de opiniones encontradas sobre la conveniencia de que se lleve a cabo bajo el auspicio municipal; 2) que ha quedado en manifiesto que no existe una aceptación general de los temas utilizados por el autor; el Intendente Municipal de Montevideo resuelve: 1) Cancelar la autorización concedida al señor Óscar Larroca para utilizar salas pertenecientes a esta Intendencia Municipal. 2) Notifíquese personalmente al señor Óscar Larroca, comuníquese al Departamento de Cultura y pase, por su orden, a los Servicios de Entrada, Trámite y Expedición y de Publicaciones y Prensa para su difusión. (FDo.) Dr. Jorge Luis Elizalde, Intendente Municipal; Diego M. Barañano, Secretario General» («La resolución de la IMM», 1986, p. 2).

5 Un caso análogo ocurrió dos años más tarde con el procesamiento con prisión de un músico de rock perteneciente al grupo Clandestino. En esta oportunidad, ya sin Elizalde como intendente, volvieron a enfrentarse las autoridades municipales y nacionales con el Departamento de Cultura. Este caso está analizado en Leandro Delgado y Federico Farachio (2017). 
Asimismo, es importante tener en cuenta la promoción de iniciativas culturales de la postdictadura que el batllismo llevó adelante con mayor o menor suerte. Durante la dictadura, había habido una proliferación de publicaciones semanales impulsadas por periodistas y políticos proscriptos, en la que se destacaron aquellos que pertenecían al batllismo (La Semana, Opinar, Jaque, Correo de los Viernes), con un espacio amplio para la información y la crítica, publicaciones que marcaron la agenda cultural de la transición democrática y la postdictadura (Álvarez Ferretjans 2008; Guinovart 2014).

En estas publicaciones participó un grupo considerable de periodistas y abogados colorados con trayectoria en la vida periodística y cultural del país, como Carlos Maggi, Manuel Flores Mora o la misma Adela Reta. Ellos incidieron en la definición de una impronta que fue distintiva del Partido Colorado en su primer gobierno, impronta que tuvo su mayor representante en el presidente Sanguinetti, como el «hombre de letras» tradicional que reunía, junto con su condición de gobernante, una participación destacada en el mundo cultural. ${ }^{6}$ Es posible pensar, entonces, que la censura aplicada unilateralmente por Elizalde no habría sido vista con buenos ojos por el mismo presidente.

Sin embargo, a pesar de su intento conciliador, la intervención del gobierno central provocó la reacción contraria, en un enfrentamiento que llamó la atención de los medios de prensa, los cuales vieron una oportunidad para construir un acontecimiento escandaloso manipulando con facilidad las opiniones principales de los políticos de todos los partidos. Esa manipulación se inició con la denuncia, por parte de la prensa, de las obras cuestionadas, desestimando la totalidad conceptual de la muestra.

\section{El ataque}

El 13 de agosto, las expresiones de varios senadores y diputados fueron publicadas en el diario El País («Políticos coinciden...», 1986, p. 7) como muestras categóricas de apoyo a la censura del intendente. La misma bajada de la nota («EL PAís mostró las obras prohibidas») logró articular tanto la presunta capacidad del diario para mostrar lo que, por su condición de «prohibidas», no podía ser mostrado como la también presunta capacidad del medio para ejercer la libertad de prensa. En realidad, la nota no

El presidente Sanguinetti ya tenía una trayectoria notoria en el ámbito de la cultura y en particular de las artes plásticas en Uruguay. Entre diversos cargos de gobierno, en 1967 fue presidente de la Comisión Nacional de Bellas Artes hasta 1973, ministro de Cultura en 1972 y presidente del Centro Regional para el Fomento del Libro de la UNESCO entre 1975 y 1984 (Fundación Konex, 2018). Escribió numerosas introducciones a estudios críticos de artistas plásticos uruguayos y publicó El Doctor Figari (Montevideo: Aguilar, 2002), sobre la vida y obra del pintor uruguayo. En su casa particular posee una importante pinacoteca de destacados artistas nacionales de todas las épocas («En la última década...», 2016). 
estaba mostrando a los lectores absolutamente nada, sino que lo había hecho exclusivamente a las personalidades entrevistadas para obtener sus opiniones, con lo que despertaba en el lector mayor curiosidad en un juego que iba y venía entre la insinuación y la represión. Así se expresaron algunos políticos:

La libertad de la que pueden gozar instituciones privadas e individuos, de exhibir este tipo de imágenes es una cosa; que el Estado patrocine y aliente exhibiciones, no solo pornográficas, sino aberrantes, nos parece que no es posible, porque la moralidad media del país no acepta como válido que esto sea arte o algo parecido. (Senador nacionalista Luis Alberto Lacalle en «Políticos coinciden...», 1986, p. 7)

Veo con cierto escepticismo las opiniones contrarias a que esto es una forma de arte; sinceramente me parece un mamarracho. (Senador nacionalista Juan Raúl Ferreira en «Políticos coinciden...», 1986, p. 7)

Estas exposiciones se financian con el dinero de impuestos que pagamos todos y no hay derecho a que una podredumbre semejante sea financiada con los recursos de todos. (Senador frenteamplista Francisco Rodríguez Camusso en «Políticos coinciden...», 1986, p. 7)

Estas declaraciones son representativas de la opinión de la casi totalidad de los políticos de la oposición, tanto del Partido Nacional como del Frente Amplio, según se lee en la prensa consultada. Con mayor o menor iracundia, se inició en los medios un desfile de declaraciones de representantes de todos los partidos que condenaban la muestra de manera implacable. Otros ejemplos se pueden transcribir de algunos subtítulos (en mayúsculas en el original) de la nota de El País.

LACALLE: ABERRANTE

JUAN RAÚL: UN MAMARRACHO

R. CAMUSSO: LOS IMPUESTOS NO SON PARA ESTO

C. J. PEREYRA: SIN BELLEZA

POZZOLO: UNA AFRENTA AL PAÍS

U. TOURNÉ: NEGATIVO MENTALMENTE

GONZÁLEZ: INTENCIÓN CASI AVIESA

TROBO: «HIEREN MI SENSIBILIDAD»

(«Políticos coinciden...», 1986, p. 7)

Estas declaraciones son matizadas sobre el final con escasas declaraciones de otros legisladores que relativizan o restan importancia al hecho. En cualquier caso, es 
importante tener en cuenta, por un lado, el mayor espacio ofrecido a las opiniones críticas y, por otro, que todas estas expresiones fueron publicadas por diarios que pertenecían a la oposición o por lo menos se ubicaban bastante lejos del batllismo.

A partir de las declaraciones iniciales de legisladores y ediles, se sucedió otra serie de críticas, ya no desde las figuras políticas sino desde las páginas editoriales, que tampoco ahorraron adjetivos contra la obra del artista censurado. Así, la crítica desde las páginas editoriales se afirmó a partir de las previas de las figuras políticas, lo que puede verse como parte de la misma estrategia de manipulación, ya que las notas editoriales tampoco fueron acompañadas de las ilustraciones censuradas, en un cercenamiento irresponsable de la información y aumentando aún más la incertidumbre del público sobre unas obras que no eran conocidas.

De esta forma, los periodistas adoptaban una actitud paternalista hacia los lectores, quienes no podían o no debían enfrentarse a obras «prohibidas», ahora con la opinión legitimadora de los legisladores. En estas editoriales, el cúmulo de agresiones hacia la obra de Larroca adquirió una creciente impronta moralista sobre la que se construyeron todas las adjetivaciones: «groseramente coprófago» («Pornografía oficializada» en El País 14 de agosto de 1986, p. 2) o «esperpento patológico» («La intendencia...», 1986) son expresiones que remiten a un discurso seudocientífico que parece ser el sustento para diagnosticar una conducta sexual trastornada.

A continuación, la crítica a Larroca y sus obras trascendió las declaraciones de políticos y periodistas para trasladarse también a figuras que, aun con influencia en la vida nacional, tenían escasa o nula participación en la opinión pública. Así aparecieron en Últimas Noticias testimonios, junto con sus fotografías, de personajes tan distantes de la vida política y cultural como el empresario Felipe Yaffé, dueño de una conocida tienda de ropa, Rodolfo Faccini, director de una empresa de transporte de cargas aéreas, y Martín Murphy, director de marketing de la tabacalera Abal Hnos. Curiosamente, los dos primeros eran contrarios a cualquier forma de censura («Brindan opinión...», 1986, pp. 2-3).

Últimas Noticias se presentó progresivamente como el principal medio difusor de la polémica, agregando otro elemento a la manipulación sensacionalista: elaboró una curiosa encuesta de opinión a los lectores respecto de las obras censuradas. El vespertino «exhibió» las reproducciones en su redacción para que los lectores interesados pudieran llegar hasta sus oficinas y dar su opinión en un formulario donde se preguntaba, en primer lugar, por el estado civil del encuestado, luego por el lugar donde las obras podían ser colgadas (hogar, estudio, oficina u otro) y finalmente si consideraba que las obras eran «artísticas», «pornográficas» o «sucias». ${ }^{7}$ redacción a completar el formulario, que se publicó en el vespertino bajo el título «Óscar Larroca nos visita» (1986, p. 3). 
Junto con el carácter protagónico que adquirió el vespertino, es importante recordar el origen de la publicación. Últimas Noticias había sido fundada en 1981, en plena dictadura, y pertenecía al Grupo Moon, un grupo económico-religioso que dirigía el reverendo Sun Myung Moon desde Corea del Sur. Su editor y director era Julián Safi, empresario que había tenido distintas posiciones periodísticas y gerenciales en el diario La Mañana — publicación de orientación pachequista- y que durante la dictadura había sido jefe de la Dirección Nacional de Relaciones Públicas (DINARP) (Scagliola, 2015). ${ }^{8}$ Con el gobierno democrático, el cargo pasó a Federico Solé, periodista de la sección política también de La Mañana.

\section{La defensa}

Todas las publicaciones referidas se concentraron en un período de dos semanas, y a ellas se sumaron algunas voces contrarias a la censura, como las declaraciones de la ministra Adela Reta, el testimonio del asesor cultural de la IMM Manuel Espínola Gómez que justifica su renuncia a la Intendencia y la declaración del Sindicato Uruguayo de Artistas Plásticos (SUAP).

Desde el primer momento de la cancelación de la muestra, el artista tuvo el apoyo del gobierno nacional no solo a través de las conversaciones que Reta y Tarigo habían tenido con el intendente, sino también en las declaraciones de la ministra a la prensa que se publicaron de manera paralela y que representaron una defensa contundente. Al relatar el encuentro con el ministro Elizalde, Reta manifestó su rechazo a todo tipo de «censura previa», negó el carácter pornográfico que acusaban medios y políticos, y finalmente ubicó la obra de Larroca en una tradición de censura en la historia de la cultura occidental.

Este problema —agregó la Ministra de Educación — viene de siglos, no hay que olvidar que Flaubert fue llevado a los Tribunales por Madame Beauvary [sic] o que la Maja desnuda de Goya no se pudo exhibir, o que se ponían hojas de parra a las estatuas que se ponían en el Vaticano, o que El Gran Masturbador de Dalí en determinado momento no se pudo mostrar y hoy es una obra maestra, o que el propio Brueghel o Goya pudieran ser controvertidos. («La constitución prohíbe...», 1986) 
La cita es significativa por varios motivos. En primer lugar, la figura de Reta era muy respetada en todos los partidos. Al momento ya era reconocida como una especialista en derecho penal, en particular sobre la minoridad infractora, había defendido a presos políticos como abogada y había presidido la Comisión de Derechos Humanos del Partido Colorado («Adela Reta», 2010). En definitiva, la intervención de Reta presentaba una opinión especializada tanto en el ámbito legal como cultural, contra la cual era difícil polemizar.

En segundo lugar, la declaración ponía de manifiesto la inconstitucionalidad de la «censura previa» y explicaba que, en todo caso, el intendente no estaría censurando sino no autorizando la exhibición en una sala municipal, por lo cual el artista podría exhibirla en cualquier otro lugar donde fuera autorizada. La misma Reta ofreció la posibilidad de hacerlo en alguna dependencia del MEC, posibilidad que finalmente se concretó en la sala Vaz Ferreira de la Biblioteca Nacional dos meses después («Estética, arte y política...», 1986, p. 16).

En este punto, es importante señalar que la ministra no empleó el término censura sino censura previa, concepto que seguramente evocaba sentidos identificados con la dictadura. La censura previa había sido un mecanismo habitual del gobierno anterior que consistía en prohibir la distribución de una publicación censurada una vez realizada la impresión y la encuadernación, con el consecuente perjuicio económico, que muchas veces resultaba en el cierre de la publicación (Guinovart, 2014). De esta forma, la declaración de Reta sugería una continuidad en las prácticas de control entre la nueva administración municipal y la dictadura.

Por último, la declaración ubicaba la obra de Larroca en el contexto de una tradición cultural occidental de censura de grandes artistas, es decir, con la cultura del resto del mundo, con la cual el país y las políticas culturales del Partido Colorado intentaban retomar contacto luego de doce años de aislamiento (Delgado, 2015). La referencia culta de Reta presentaba, al mismo tiempo, dos dimensiones de la noción de cultura: una entendida como valor o ideal de un plan civilizatorio y la otra como la herencia documental que las generaciones de Occidente habían dejado tras de sí (Williams, 1994) y que el país debía retomar. Así, la declaración de Reta no solo confirmaba la intención de establecer una política cultural determinada desde su ministerio; también exhibía un dominio de referencias y nociones culturales que definían una figura pública de gobernante ilustrado que representaba fielmente, a su vez, a la figura letrada del presidente Sanguinetti.

El 14 de agosto El País y Últimas Noticias informaron de la renuncia del asesor plástico Espínola Gómez. Mientras la información de El País se concentraba en las declaraciones del asesor sobre la desinteligencia de considerar las obras como «pornográficas» («Esto Demuestra...», 1986), Últimas Noticias reproducía las declaraciones del exasesor que se enfocaban en otro aspecto de la manipulación periodística, en 
particular la descontextualización de los dibujos al ser mostrados a los políticos en soporte fotográfico, así como la fragmentación y la «mutilación» de los trabajos con el mismo propósito («Renunció Espínola Gómez...», 1986).

La referencia a la mutilación es importante porque volvió a ser empleada en la declaración del Sindicato Uruguayo de Artistas Plásticos (SUAP). Allí se denunció tanto la manipulación sensacionalista de Últimas Noticias a través de su encuesta como de la fragmentación de las obras por parte de toda la prensa, en una operación que vulneraba los propios derechos del artista, quien veía cómo su obra era reproducida y distorsionada sin su permiso y con fines difamatorios. Quizá lo más interesante de esta declaración sea la sorpresa del propio sindicato ante la reacción desmedida frente a un tema de la cultura, de la cual la prensa muy poco se había ocupado hasta entonces («Declaración del SUAP ...», 1986).

En la declaración del SUAP se hace un énfasis especial en la prohibición como manifestación de una «política claramente anticultural»y, por la misma causa, de una falta de educación de la sensibilidad para una comprensión profunda de los fenómenos artísticos. Las defensas de Reta, Espínola Gómez y el SUAP sin duda resultan articuladas y bien fundamentadas, no solo por las razones manejadas sino por la oportunidad para vincular la situación vivida por el artista con la represión de las manifestaciones culturales ejercida en el pasado.

Aquí se puede reflexionar acerca de lo que el SUAP definió o diagnosticó como «política anticultural» a la luz del concepto de habitus, porque puede ofrecer una explicación al repudio generalizado de los políticos de todos los partidos. Según el concepto acuñado por Pierre Bourdieu, existe una relación entre el campo de poder y el campo intelectual determinada por una clase dominante que establece aquello que puede ser visto con naturalidad como manifestación cultural en la medida en que corresponde con los valores y los patrones culturales admitidos y promovidos por esta clase. ${ }^{9}$

La censura a Larroca, entonces, se presentaba como una revelación de cierto habitus que todavía resultaba frágil, o en plena conformación, en los primeros años de la nueva democracia y como una visualización de los imprecisos límites entre los campos de poder de la dictadura y de la democracia sucesivamente, el primero combatiendo el nuevo campo intelectual, el segundo plasmándose progresiva y definitivamente en una red cultural cada vez más extensa. Esta suerte de solapamiento o superposición de cam- 
pos de poder resultaba, posiblemente, de la forma en que había sido alcanzada la salida de la dictadura, es decir, entendida como transición (Achard, 1995; Caetano y Rilla, 2006).

La inesperada llegada de Elizalde no solo habría interrumpido la conformación progresiva del habitus democrático, sino que puso en evidencia hasta dónde tal conformación estaba limitada o condicionada por el campo de poder de la dictadura, que todavía resultaba activo no solo a través de las acciones del intendente o de las manipulaciones sensacionalistas de la prensa vinculada a la dictadura, sino también de los mismos políticos que habían pertenecido a la oposición durante el régimen militar. En este punto, se puede comprender cómo la noción de habitus entiende el poder como interiorizado por los ciudadanos, en este caso particular a través de los mecanismos de la censura y la represión recientes, hasta el punto de no poder ver, en la nueva democracia, las expresiones originales que surgían fuera del sistema de valores determinado por la dictadura. ${ }^{10}$

Sin embargo, en este cúmulo de noticias difamatorias, en el ruido creado por la superposición de opiniones y de editoriales que seguían denostando a Larroca y a sus obras sobresale, inesperadamente, un acontecimiento que vino a zanjar definitivamente la polémica casi sin decir palabras: la intervención visual y anónima de la escultura del David en la misma fachada del edificio de la IMM.

\section{La intervención}

El martes 14 de agosto, Últimas Noticas publicó en su portada una foto de gran tamaño del monumento del David ${ }^{11}$ sorpresivamente cubierto, la noche anterior, con una tela blanca que le rodeaba la cintura y bajo el título «El David amaneció en pañales». La gran escultura iba acompañada de una pancarta que decía: «Defendamos la moral. Brigada "Amigos de J. Elizalde"». El humor de la intervención parecía transmitirse tanto al título de la nota como a su bajada, que a fuerza de ser sarcástica resultaba poco comprensible: «¿Víctima de la intolerancia o la inclemencia del tiempo?» (figura 4).

«El principio unificador y generador de todas las prácticas, y en particular de las orientaciones habitualmente descritas como "elecciones" de la "vocación" o directamente como efectos de la "toma de conciencia", no es otro que el habitus, sistema de disposiciones inconscientes producido por la interiorización de estructuras objetivas. Como lugar geométrico de los determinismos objetivos y de las esperanzas subjetivas, el habitus tiende a producir prácticas (y en consecuencia carreras) objetivamente adherentes a las estructuras objetivas» (Bourdieu, 2002, p. 118, mi énfasis).

11 La escultura tiene un gran valor simbólico, tanto por tratarse de una obra de Miguel Ángel como por ser una de las escasas réplicas en bronce del original. 


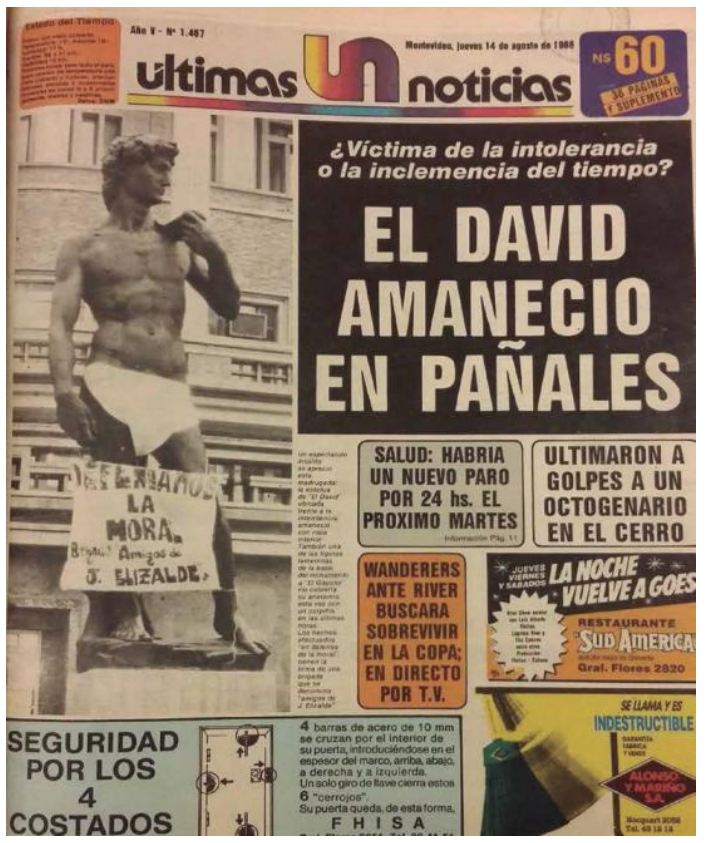

Figura 4. Portada de Últimas Noticias

En su página interior, junto al resto de las noticias sobre la renuncia de Espínola Gómez y la declaración del SUAP, solamente una pequeña crónica titulada «Strip-tease del David» (1986) describe la intervención. Es significativa la diferencia entre el tamaño de la foto de portada y la extensión mínima de la crónica. La sorpresa del cronista, y seguramente de los responsables editoriales de Últimas Noticias frente a la intervención visual, no habilitaba a una reflexión sencilla, lo cual se transmitía no solo en pocas palabras sino en una escasa claridad:

Si se tiene sentido del humor, estos hechos pueden parecer divertidos, satíricos, acertadamente críticos contra una decisión de censura hacia un artista. Ahora, si uno se ubica en la posición del artista que creó las obras «vestidas», la creación no debe ser graciosa. Las fotografías son elocuentes para todos los que no apreciaron «en vivo y en directo» el fenómeno de esta brigada, y permiten que cada uno, de acuerdo a su real entender y valorar, saque sus conclusiones. («Striptease del David», 1986)

Sin embargo, la crónica estuvo acompañada por un despliegue visual significativo: una secuencia de cuatro fotos donde se puede ver a los funcionarios de la IMM en el proceso de retirar la tela de la escultura con una escalera. De esta forma, la acción de 
los funcionarios municipales, en el proceso del descubrimiento de la tela, se convierte también en parte de la intervención: si la intención inicial de los interventores anónimos había tenido como primer objetivo la denuncia de la censura, el cubrimiento de la zona genital del David parecía aludir a la genitalidad censurada en la obra de Larroca. Ahora, el registro fotográfico del descubrimiento obligaba a los funcionarios municipales (y por extensión a la institución municipal) a tener que descubrir el cuerpo, en una operación inversa a la censura, que hacía públicamente visible el cuerpo desnudo de una obra de arte por parte de las mismas autoridades (figura 5).

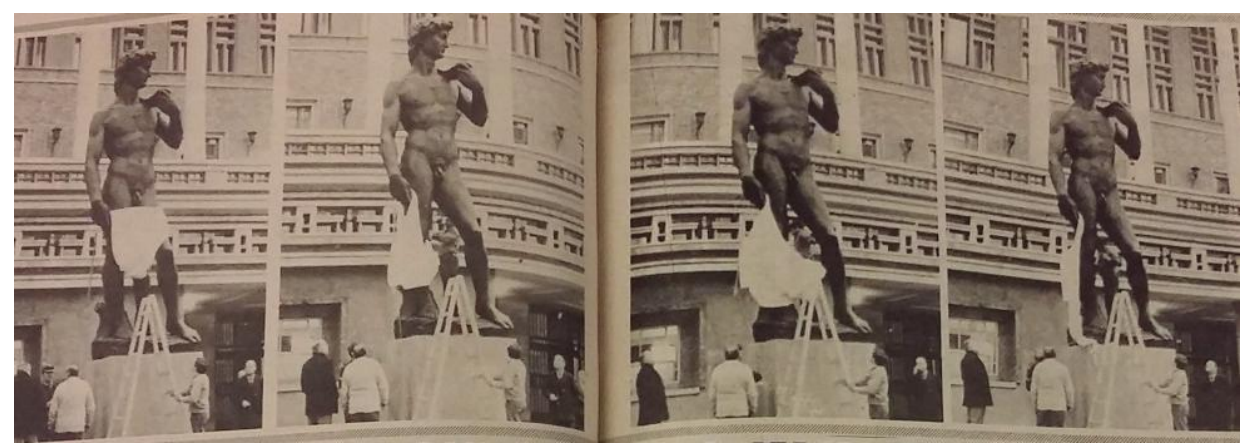

Figura 5. Secuencia de fotos del vespertino Últimas Noticias

Por otra parte, el propio título de la crónica («Strip-tease del David») parece referir a una suerte de cultura prostibularia, como si el único modo de entender el desnudamiento de un cuerpo tuviera que implicar cierta forma de degradación. La intervención ponía así de manifiesto no solo la posición conservadora de parte de la prensa en general y de Últimas Noticias en particular, sino también cómo la mirada conservadora de la sexualidad resultaba la contracara de una suerte de mirada degradante como la única posible para comprender la exhibición pública de un cuerpo. La intervención ponía en evidencia distintas formas de una concepción prejuiciosa del cuerpo desnudo (de parte de autoridades y medios de prensa) que había sido desplazada y proyectada espectacularmente sobre las obras de Larroca.

La intervención había sido realizada con bastante conocimiento de las agendas mediáticas. Los interventores eran estudiantes de Comunicación Social de la Universi- 
dad Católica del Uruguay ${ }^{12}$ y estaban en conocimiento tanto de las rutinas periodísticas como de las posibilidades espectaculares de la comunicación visual. Así, una vez realizada la intervención, ellos mismos llamaron a los medios de prensa para dar a conocerla desde un bar ubicado frente a la IMM. Solo acudió un fotógrafo de Últimas Noticias, el d que se había convertido en protagonista de la manipulación informativa.

La intervención de los cuatro estudiantes fue efectiva por varios motivos. En primer lugar, reafirmaba la visibilidad del cuerpo artístico desnudo en el espacio urbano. En segundo lugar, lograba captar la atención de la prensa a partir de su conocimiento de las formas de trabajo de la prensa: Últimas Noticias aún estaba a tiempo de asistir al registro a primeras horas de la mañana porque se publicaba y se vendía en la tarde. En tercer lugar, establecía la crítica a la censura en términos visuales y no verbales, no solo desestimando la violencia verbal y el ruido injustificado en torno al suceso, sino estableciendo una conexión directa con la visualidad censurada de las obras.

La celeridad con que los funcionarios municipales desvistieron al David a primeras horas de la mañana permite pensar en el impacto visual de la intervención, dada además la ubicación del monumento, en la fachada de la Intendencia, así como del mismo edificio, en un punto de intensa circulación en la ciudad. La intervención habilita, entonces, a reflexionar sobre la imbricación entre medios de comunicación y espacio urbano. Y aunque no lo afirme, Henri Lefebvre (2013) se pregunta si una obra arquitectónica o urbana puede considerarse, en sí misma, una forma particular o inusual de medio de comunicación, entendiendo el espacio social como lenguaje o discurso. ${ }^{13}$

En cualquier caso, el espacio que abarcó la sala de exposiciones, las oficinas municipales donde se tomaron las decisiones, la fachada del edificio flanqueada por el David e incluso el bar frente a la IMM se revela de pronto en su totalidad como un mismo espacio complejo, entramado y definido por las relaciones humanas, un espacio donde se vieron desplegadas las negociaciones y los desencuentros, los acuerdos y las expectativas de grupos e individuos con intereses diversos. En este aspecto se puede ver cómo la intervención, entendida como una práctica particular del uso de la ciudad, se realiza por fuera de lo admitido o esperado en la ciudad ordenadora, intervención que permitió revelar otra espacialidad donde se manifestaban relaciones y acciones por detrás de la ciudad visible.

12 Entre los integrantes de la Brigada y estudiantes de la Universidad Católica se encontraban la productora audiovisual Irene Pepi Goncalvez (Belén Díaz, comunicación personal, 5 de noviembre de 2015) y el periodista Leonardo Haberkorn (Belén Díaz, comunicación personal, 20 de julio de 2016).

13 Así pues, es posible plantear las siguientes cuestiones, perfectamente legítimas: a) ¿Tienen significado los espacios formados por la actividad práctico-social, los paisajes, los monumentos o las construcciones? b) ¿Puede considerarse mensaje el espacio ocupado por uno o varios grupos sociales? c) ¿Debe concebirse la obra (arquitectónica o urbana) como un caso notable aunque inusual de mass-media? d) ¿Puede un espacio social ser concebido como lenguaje, como discurso, dependiente de una práctica definida (la lectura-escritura)? (Lefebvre, 2013, p. 183). 
Michel de Certeau señala aquellos usos y prácticas urbanos que no obedecen al dictado ordenador de la ciudad geométrica y que, por el contrario, revelan otra espacialidad que contiene otras realidades (1988). Aún más, afirma la necesidad de detectar cómo una sociedad que fluye en la trama urbana se resiste a ser reducida a los movimientos determinados por su diseño disciplinador justamente a partir de la forma en que los mismos ciudadanos logran manipular estos mecanismos con la finalidad de evadirlos. ${ }^{14}$

El monumento del David y la fachada de un edificio emblemático — que concentra la administración y el control de la ciudad - son elementos ordenadores en un trazado urbano que determina, en los términos planteados, una omnipresencia disciplinante en la vida urbana, elementos que adquirieron, en el contexto general de la postdictadura y en el particular de la censura, una visualización crítica. La intervención irreverente a la estatua constituyó una manipulación efectiva porque logró poner en evidencia el disciplinamiento desde una ridiculización que, en los términos de De Certeau, lograba aprovechar o reapropiar la manifestación visual del poder en beneficio de unos actores marginales, en este caso los jóvenes interventores. El desnudamiento del monumento por las mismas autoridades municipales y su registro fotográfico ayudan a comprender esta inversión del poder en beneficio de una reivindicación marginal y anónima.

La visualización crítica del trazado urbano ordenador se puede problematizar aún más desde la perspectiva de la ciudad letrada, según el concepto acuñado por Ángel Rama (1998). En sus términos, desde la conquista de América y el avance colonizador, existe una ciudad que corresponde al orden material y que está sometida a los avatares de su crecimiento o destrucción. A esta ciudad se superpone otra de orden simbólico que se origina justamente desde su fundación, dado el carácter planificado de las ciudades del continente de acuerdo con los criterios territoriales determinados por las Leyes de Indias. Esta ciudad letrada estaba conformada por un universo simbólico y normativo determinado por la acción de burócratas, jueces, notarios, sacerdotes y otros funcionarios coloniales que administraron la sociedad a través de la palabra escrita, extremadamente formalizada, de los documentos, leyes y decretos, y que tuvo particular relevancia en la organización de todos los órdenes de la vida colonial. Es relevante, además, considerar que la ciudad letrada actúa en el nivel de las significaciones, mientras que la ciudad real estaría actuando en el registro de los significantes (p. 40).

De Certeau explica que el interés de su análisis sobre las prácticas urbanas reside en localizar aquellas prácticas «que son externas al espacio "geográfico" o "geométrico" de construcciones visuales, panópticas o teóricas. Estas prácticas de espacio refieren a formas específicas de operaciones ("formas de operar"), a "otra espacialidad" (una experiencia del espacio "antropológica", poética y mítica) y a una movilidad opaca y ciega característica de la ciudad bulliciosa. Una ciudad migracional o metafórica se desliza en el texto claro de la ciudad planificada y legible"» (De Certeau, 1988, mi traducción, énfasis de De Certeau, p. 93). 
A lo largo de la historia existen, no obstante, encuentros y desencuentros entre la ciudad real y la letrada, tanto por las desavenencias, tensiones y conflictos dentro de las elites criollas como por su forzosa imposición de derechos y deberes al resto de la sociedad, la plebe, que se encontraba fuera de los planes de educación coloniales (y, por consiguiente, del acceso a una lengua formalizada). Es posible entonces ubicar el episodio de la intervención al David como una tensión o vaivén entre la ciudad material y la simbólica, así como establecer las implicaciones en las interpretaciones de este acontecimiento en el contexto de la postdictadura.

La interpretación que surge con más elocuencia es, justamente, la crítica a la ciudad letrada entendida como un sistema de símbolos disciplinantes que debía ser combatido, resistido o evadido. En este caso, la totalidad de los mecanismos administrativos y burocráticos se visualizaba en el edificio. Se trataría entonces de una crítica a un sistema simbólico y ordenador que se percibía, en gran medida, como una continuación del autoritarismo de la reciente dictadura y que, en la censura a Larroca, se puso de manifiesto no solo a través de comunicados y resoluciones oficiales, sino también en el volumen considerable de textos periodísticos publicados en los días anteriores, cuando la prensa amplificó la posición represora de abogados, jueces, legisladores, ministros y otros funcionarios municipales y de gobierno. La intervención dejaba en evidencia una censura del gobierno municipal no de acuerdo con criterios artísticos o culturales determinados, sino, por extensión, con una forma represiva, conservadora y degradante de concebir la sexualidad.

Una segunda interpretación permite pensar, al contrario, en un encuentro o coincidencia entre la ciudad material y la letrada. La intervención del monumento concentraba la mirada pública sobre una obra de arte clásica que correspondía a una tradición cultural determinada y aceptada por los integrantes del gobierno, principalmente los pertenecientes a los sectores batllistas que actuaron o se manifestaron en defensa del artista (Adela Reta, Enrique Tarigo). En consonancia, el descubrimiento de la tela, al modo de la inauguración de cualquier monumento, afirmaba la marca del arte clásico en la tradición cultural nacional, no por una toma de posición esquemática o previsible de los artistas entre el arte clásico y el arte de vanguardia, sino por una reafirmación de la importancia dada a la cultura frente a su represión, intervención e irrupción, en todos sus ámbitos, en los años anteriores, acciones que habían aislado a Uruguay de la producción cultural del resto del mundo.

Esta posibilidad de visualizar las coincidencias y los desajustes entre la ciudad material y la letrada parece surgir de la circunstancia particular de la reivindicación, la cual dejaba de lado la comunicación verbal y empleaba los recursos de la comunicación visual. Fuera de la pancarta irónica que acompañaba la sábana («Defendamos la moral...»), y aun teniendo en cuenta la ausencia física de los interventores para garantizar el anonimato, el acontecimiento reúne varios rasgos que lo acercan a una acción performática. Diana Taylor (2011) problematiza la definición de performance y destaca su naturaleza 
antiinstitucional la cual resulta, en sí misma, un acto político, entendido lo político como una posición de ruptura más que una posición ideológica específica. Ante todo agrega- la performance se ubica más allá de la representación, dificultando la distinción entre la representación y su referente real con respecto a una situación particular.

Este alcance de la performance que dificulta las distinciones entre significado y significante tiene implicaciones importantes en la concepción de la ciudad letrada. En primer lugar, permite reflexionar sobre el poder del acto performático para desestimar las concepciones que, como las de Rama, ven en la ciudad un mundo simbólico determinado por una cultura escritural que estaría operando sobre la ciudad material. Aún más, la acción performática lograba exhibir no solo la complejidad del entramado de relaciones de poder de pronto expuesta al público, sino que, paradójicamente, negaba todo carácter simbólico al concentrar la atención en la materialidad de la acción, del monumento y del edificio, desestimando, todo a un tiempo, las interpretaciones discursivas tradicionales. Esta suspensión momentánea de todos los significados posibles que habían sido evocados por el episodio de censura dentro del edificio municipal permitía visualizar o intuir, también de manera efímera, otro mundo posible donde la libertad se presentaba, todavía, como necesidad y horizonte.

\section{Conclusiones}

El análisis del debate en la prensa permitió reconstruir los conflictos existentes dentro del Partido Colorado entre los sectores batllistas y pachequistas en la nueva democracia. En este sentido, el episodio de la censura identificaba al pachequismo como continuador de las medidas represivas en el ámbito de la cultura y al batllismo como la garantía de su reconstrucción. Sin embargo, el rechazo colectivo, también de aquellos políticos que habían sido opositores a la dictadura, permitió reflexionar hasta qué punto los mecanismos de represión de los años previos habían sido interiorizados por los representantes de la democracia prolongando una conducta autoritaria más allá del 1 de marzo de 1985.

Es importante analizar la obra de Óscar Larroca de la postdictadura entendida como una estetización o visualización de las expectativas de las subculturas juveniles de los ochenta. Se puede analizar el juego entre éxtasis y abyección, entre hedonismo y paranoia o entre erotismo y destrucción como parte de la compleja sensibilidad de los jóvenes de la nueva democracia, que tuvo su correlato en otras manifestaciones como el rock, el teatro o la poesía.

También es importante reflexionar sobre las intervenciones urbanas en particular como una manifestación cultural de las nuevas generaciones, a través de la cual lograron ponerse en pie de igualdad en el debate político empleando la acción per- 
formática como una acción política no verbal que venía a transformar las formas de comprender la participación. En su indefinición entre lo representado y lo real, la performance se presenta como un rasgo característico y novedoso de las luchas políticas que se instalaron en la posmodernidad y que entrarían en conflicto con las formas tradicionales de participación llevadas adelante por las generaciones anteriores.

Asimismo, es importante tener en cuenta que el éxito particular de esta intervención fue posible, en gran medida, porque los jóvenes participantes lograron emplear a su favor los medios de prensa gracias al conocimiento cabal de las rutinas periodísticas, un conocimiento permitido por la llegada de los estudios de comunicación a Uruguay. Estos estudios - extensivos a todo el continente latinoamericano- resultaron atractivos y novedosos para un grupo considerable de jóvenes del período. Su atractivo particular puede ser analizado, también, como otro rasgo cultural definitorio de la generación de los ochenta.

\section{Bibliografía}

ACHARD, D. (1995). La transición en Uruguay. Montevideo: Ediciones de la Banda Oriental. «Adela Reta» (2010). Mujeres que hacen la historia. Recuperado de https:// mujeresquehacenlahistoria.blogspot.com/2010/03/siglo-xx-adela-reta.html.

Álvarez Ferretjans, D. (2008). Desde La Estrella del Sur a Internet: Historia de la prensa en el Uruguay. Montevideo: Fin de Siglo.

Bourdieu, P. (2002). Campo de poder, campo intelectual. Buenos Aires: Montressor. «Brindan opinión empresarios» (14 de agosto de 1986). Últimas Noticias, pp. 2-3.

Caetano, G. y Rilla, J. (2006). Breve historia de la dictadura. Montevideo: Ediciones de la Banda Oriental.

DACRuZ, P. (29 de octubre de 2010). «Con Óscar Larroca: La intimidad de la imagen». El País Cultural, Recuperado de https://artepedrodacruz.wordpress.com/2010/ 11/15/con-oscar-larroca-la-intimidad-de-la-imagen-2/.

DeCerteau, M. (1988). The practice of everyday life. Berkeley: Prentice Hall. «Declaración del SUAP ante la muestra» (14 de agosto de 1986). Últimas Noticias.

DELGADO, L. (2015). «La subcultura juvenil del punk-rock montevideano en la crítica musical y cultural de los ochenta (1983-1987)». Revista Afuera 15(1). Recuperado de http://www.revistaafuera.com/articulo.php?id=329\&nro=15.

DELGADO, L. y FARACHIO, F. (2017). «Rock de la cárcel: El caso Clandestino en la nueva democracia». Dixit, 27, 88-104.

«Dibujos de Larroca no serán patrocinados por la IMM; Directores de Cultura podrían dimitir». (14 de agosto de 1986). Búsqueda, p. 15. 
«En la última década se perdió aquello de mirar hacia arriba: Entrevista a Julio María Sanguinetti» (3 de enero de 2016). El País. Recuperado de https://www.tvshow. com.uy/arte/ultima-decada-perdio-mirar.html.

«Estética, arte y política municipal» (13 de agosto de 1986). Alternativa Socialista, p. 16.

«"Esto demuestra falta de cultura integral”, afirma dimitente Asesor Plástico» (14 de agosto de 1986). El País.

Fundación KoneX (2018). Julio María Sanguinetti (Uruguay). Recuperado de https:// www.fundacionkonex.org/b3083-julio-maria-sanguinetti-uruguay.

GuinovarT, R. (2014). «Jaque: entre la ideología y el partido». En L. Delgado (ed.), Cultura y comunicación en los ochenta (pp. 19-34). Montevideo: Biblioteca Nacional. (Cuaderno de Historia, 13)

HABer, A. (s.f.). Manuel Espínola Gómez: Datos biográficos". Recuperado de http:// muva.elpais.com.uy/Esp/info/manuel_espinola_gomez/biografia.html.

«Intendente: Obras van hasta las perversiones sexuales» (13 de agosto de 1986). El País, 7. «La Constitución prohíbe censura previa dijo Reta» (13 de agosto de 1986). El País.

«La intendencia y el arte» (12 de agosto de 1986). La Mañana.

«La resolución de la IMM » (12 de agosto de 1986). Últimas Noticias.

Lefebvre, H. (2013). La producción del espacio. Madrid: Capitán Swing.

«Óscar Larroca nos visita» (12 de agosto de 1986). Últimas Noticias, p. 3.

«Pedido de informes a Reta y Elizalde por muestra pornográfica» (12 de agosto de 1986). El País, p. 4.

«Políticos coinciden en que se podrán exhibir pero con "Franja Verde"» (13 de agosto de 1986). El País, p. 7.

«Pornografía oficializada» (11 de agosto de 1986). El País, p. 2

«Presuntas irregularidades en la Intendencia» (10 de abril de 1986). Alternativa Socialista.

«Puntualizaciones de Elizalde a la Junta» (14 de agosto de 1986). Últimas Noticias.

RAMA, Á. (1998). La ciudad letrada. Montevideo: Arca.

«Renunció Espínola Gómez» (14 de agosto de 1986). Últimas Noticias.

SCAgliola, R. (9 de julio de 2015). «La tinta del Cóndor». La Diaria. Recuperado de https://ladiaria.com.uy/articulo/2015/7/la-tinta-del-condor/.

«Strip-Tease del David» (14 de agosto de 1986). Últimas Noticias, p. 3.

TAYLOR, D. (2011). «Introducción: Performance, teoría y práctica». En D. TAYlor y M. FUENTES (eds.), Estudios avanzados de performance (pp. 7-30). México: Fondo de Cultura Económica.

«Un profesor de la Fac. de Derecho al frente de la IMM» (14 de diciembre de 1985). Búsqueda, p. 11.

Williams, R. (1994). «The analysis of culture». En J. Storey (ed.), Cultural theory and popular culture: A reader (pp. 48-56). Harlow: Prentice Hall. 